\title{
Angiographic investigation of patients with transient ischaemic attacks
}

\author{
EDMUND H. BURROWS AND JOHN MARSHALL
}

\author{
From the Lysholm Radiological Department and the University Clinical Unit, the National Hospital for Nervous \\ Diseases and Institute of Neurology, Queen Square, London
}

Among the various manifestations of cerebrovascular disease none is more important than the phenomenon of transient ischaemic attacks. This importance stems from the fact that, though these short-lived disturbances of neurological function may continue for years without apparent detriment to the patient, they often give warning of an impending stroke. Most commonly they are associated with atherosclerosis; in addition there are precipitating factors which include anaemia (Siekert, Whisnant, and Millikan 1960,) polycythaemia (Millikan, Siekert, and Whisnant 1960), hypotensive episodes (Denny-Brown and Meyer, 1957), hypertensive episodes (Kendell and Marshall, 1963), and rheumatic endocarditis (Hutchinson and Stock, 1963). As these precipitating factors occur in only a small proportion, probably not more than $5 \%$, of the patients who come with transient ischaemic attacks as their presenting complaint, it is important to obtain further understanding of the genesis of their attacks and this may be achieved by visualizing the vessels supplying the brain by angiographic means.

Although there have been many reports of extensive series of patients with cerebrovascular disease studied by angiography (Gurdjian, Lindner, Hardy, and Webster, 1960; Meyer, Sheehan, and Bauer, 1960; Bauer, Sheehan, and Meyer, 1961; Müller, Greitz, Liliequist, and Hellström, 1964), most have included so wide a variety of types of cerebrovascular disease that it is difficult to determine the pattern of angiographic findings at the stage when the patients are experiencing only transient ischaemic attacks. Poser, Snodgrass, and Faris (1962), however, utilizing a catheter introduced via the brachial artery, studied 89 patients with intermittent cerebrovascular insufficiency and found that of the 288 vessels visualized, $109(38 \%)$ showed some abnormality, 66 patients having a lesion of some kind. The present study was undertaken to supply further information upon this type of case.

MATERIAL

The study is concerned with 66 consecutive patients who presented with transient ischaemic attacks, 59 of whom were studied by angiography and seven were not. In the latter group, one, a man of 63 years (C.V. no. 699) was severely anaemic (haemoglobin $5.4 \mathrm{~g}$.); his attacks ceased when the anaemia was corrected by blood transfusion. A second man (C.V. no. 602) aged 75 years, had experienced over 100 attacks of loss of vision in the left eye during the preceding 12 months. A harsh, well-localized bruit was present over the bifurcation of the left common carotid artery. He was thought to have a carotid stenosis giving rise to emboli, but in view of his age angiography was not performed, nor anticoagulants given. Eight months later, following an attack, vision did not recover in the left eye and examination a few days later showed that the bruit had disappeared, presumably due to the stenosis having become an occlusion. A third patient, a woman of 59 years, was suffering from episodes of atrial fibrillation, hence was not subjected to angiography. Two other female patients declined investigation and in two male patients attempts at angiography were unsuccessful. The distribution by age, sex, and arterial territory in which the transient ischaemic attacks were occurring in the remaining 59 patients is given in Table $I$.

\section{TABLE I}

DISTRIBUTION OF PATIENTS BY MEAN AGE, SEX, AND SITE OF TRANSIENT ISCHAEMIC ATTACKS

\begin{tabular}{lllll} 
Site & \multicolumn{2}{l}{ Male } & Female & Total \\
\hline Carotid & $32(56 \mathrm{yr})$. & $3(61 \mathrm{yr})$. & 35 \\
Vertebro-basilar & $17(55 \mathrm{yr})$ & $7(56 \mathrm{yr})$ & 24 \\
Total & 49 & 10 & 59
\end{tabular}

ANGIOGRAPHIC METHODS In the early part of this study only the vessel in the territory of which the transient ischaemic attacks were believed to be occurring was examined angiographically. Thus a right-handed patient with transient episodes of dysphasia would have the left carotid system examined by direct puncture of the common carotid artery. It soon became apparent that this limited examination was inadequate. If a carotid stenosis was found, the condition of the opposite carotid artery had to be assessed before surgery could be contemplated, and so direct puncture of two arteries supplying the brain was required with the risks that this involves (Crawford, 1956). In the case of the vertebral artery, direct puncture can never show the origin of the artery from the subclavian, which is the commonest site at which a stenosis 


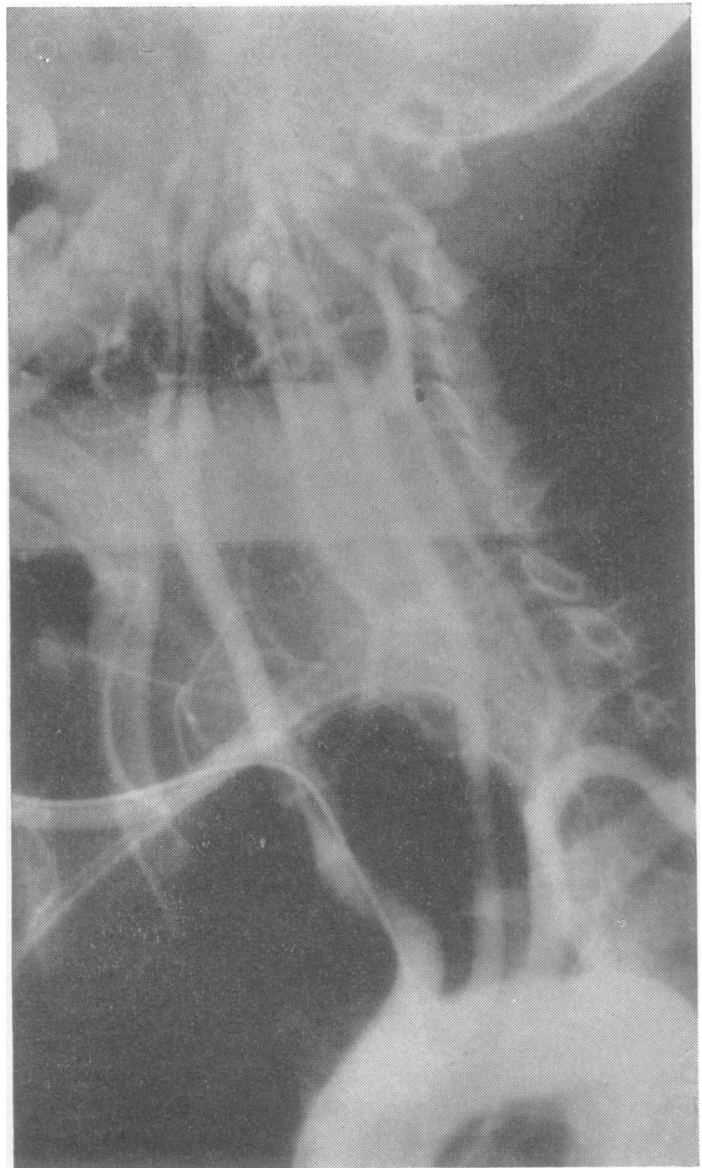

FIG. 1. Four-vessel angiography via the right axillary artery. There are lesions at the origins of both internal carotid arteries.

may be expected to be found. For these reasons a change was made to angiographic examination via a catheter passed into the aorta.

Various routes were used to introduce the catheter (the brachial artery being employed once, the femoral artery 12 times, and the axillary artery 26 times); of these the axillary route, as described by Newton (1963), was undoubtedly the most satisfactory (Fig. 1). The axillary artery is readily accessible for percutaneous puncture, the length of catheter and guide-wire required is shorter than for either the brachial or femoral route which makes both the maintenance of sterility and manipulation easier and, because of the size of the lumen, the pulse is not obliterated during the procedure. The benefit gained by changing from direct puncture of a single artery to catheterization is illustrated in Table II, where it is shown that in the carotid system the percentage of cases in which an abnormality was found rose from 14 to 66 .

Use of the right axillary artery offers certain advantages, in that selective right vertebral angiography and right
TABLE II

RESULTS OF ANGIOGRAPHY IN CAROTID TRANSIENT ISCHAEMIC ATTACKS IN MALES ONLY

No. of Patients No. with an Percentage Examined Abnormality

One vessel examined

by direct puncture

Two vessels examined

by direct puncture

Four vessels examined

by catheter

3

15

10

66

carotid angiography is possible in the course of the procedure. A $40 \mathrm{~cm}$. long polythene catheter (size P.E. 240 with an external diameter of 0.095 inch and a bore of $\overline{\bar{\omega}}$ 0.066 inch and with three or four side holes), was advanced from the axillary artery until the tip lay in the innominate artery. An injection by hand at this stage of $15 \mathrm{ml}$. of contrast medium (Hypaque $45 \%$ ) gave excellent $\vec{\circ}$ visualization of the right vertebral and carotid trees, including their intracranial parts. A notable advantage of $\overrightarrow{\vec{\omega}}$ innominate injection is the crisp detail of these vessels, and particularly of the vertebrobasilar tree intracranially, $\overline{\vec{Z}}$ which may not be achieved by injection into the aortic $\frac{7}{0}$ arch due to contrast dilution. Following innominate is injection, the catheter was advanced so that the tip lay $\infty$ in the ascending aorta. An arch aortogram was now of performed. A large volume of high concentration (40 mb of Hypaque $85 \%$ ) was injected under pressure (50 150 per sq. foot) with the patient lying in the left anteriof oblique position to open out the aortic arch and so better to visualize the origins of the great vessels. With carefe् $\mathbb{D}$ positioning of the patient, it was possible to visualize the aortic arch as well as the major vessels at the base the brain in a single rapid series of films. If the left internal carotid tree was not sufficiently well seen intri cranially, a second pressure injection was made into the $\vec{\varphi}$ aortic arch and an antero-posterior skull series taken. or Although the appearances are vitiated by contrast dilution, the angiographical midline structures are always well seen.

In the 26 cases in which the catheter was passed via the right axillary artery the right vertebral circulation was $\stackrel{0}{\varnothing}$

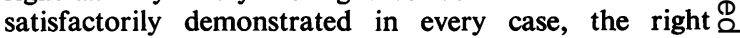
carotid circulation in 24 , the left vertebral in 20 , and the $\overrightarrow{\vec{A}}$ left carotid in 17. The entire left side of the circulation $\frac{0}{3}$ to the brain was outlined in 16 cases $(61 \%)$. There were no complications in this series following this procedure.

ANGIOGRAPHIC FINDINGS IN CAROTID TRANSIENT ISCHAEMIC ATTACKS

As the natural history of transient ischaemic attacks in the carotid and vertebrobasilar territories is 8 strikingly different (Marshall, 1964), the results of $₹$ angiography in the two groups will be consideredo separately.

Among the 35 patients with attacks in the carotido territory, 13 had abnormal angiograms. When it is remembered that in 14 of the 35 patients only oneos vessel was examined, it will be seen that the per- $N$ 
centage of patients with transient ischaemic attacks in which angiographic abnormalities may be expected is high. The details of the lesions found are given in Table III, which shows that the majority were at sites accessible to the surgeon. Multiple lesions were present in eight patients in all

\section{TABLE III}

ANGIOGRAPHIC LESIONS IN 35 PATIENTS WITH CAROTID TRANSIENT ISCHAEMIC ATTACKS

\begin{tabular}{lll} 
Lesion & Unilateral & Bilateral \\
\hline Common carotid stenosis & 1 & - \\
Internal carotid stenosis & 3 & 2 \\
Internal carotid occlusion & - & 1 \\
Vertebral stenosis & 4 & - \\
Subclavian stenosis & 2 & - \\
Subclavian 'steal' & 1 & - \\
Middle cerebral occlusion & 1 & - \\
Anterior cerebral occlusion & 1 & - \\
Gross vertebral indentation by osteophytes & 2 (patients) & -
\end{tabular}

\section{ANGIOGRAPHIC FINDINGS IN VERTEBROBASILAR TRAN- SIENT ISCHAEMIC ATTACKS}

Among the 24 patients with attacks in the vertebrobasilar territory there were 17 with abnormal angiograms, five having multiple lesions. The details of all the lesions found are given in Table IV.

\section{TABLE IV}

ANGIOGRAPHIC LESIONS IN 24 PATIENTS WITH VERTEBROBASILAR TRANSIENT ISCHAEMIC ATTACKS

Lesion Unilateral Bilateral

Innominate stenosis

Internal carotid stenosis

External carotid stenosis

Verterbral stenosis

Basilar stenosis

Subclavian steal

Vertebral indentation by osteophytes

$\begin{array}{ll}2 & - \\ 2 & 2 \\ 2 & - \\ 1 & - \\ 1 & - \\ 10 \text { (patients) } & -\end{array}$

One of the patients with multiple lesions showed occlusion of both internal carotid arteries at their origin (Fig. 2) and a stenosis of one vertebral artery. He was a man of 63 years (C.V. no. 110) with a five-year history, first of several attacks of blurring of vision with weakness of the right arm each lasting 15 minutes, and later of two attacks of complete loss of vision in both eyes each for a period of 10 minutes.

A striking feature among the patients with vertebrobasilar transient ischaemic attacks was the high incidence of severe indentation of the vertebral arteries by osteophytes due to cervical spondylosis (Fig. 3). Table $\mathrm{V}$ shows that vertebral artery indentation was tvice as common in patients with

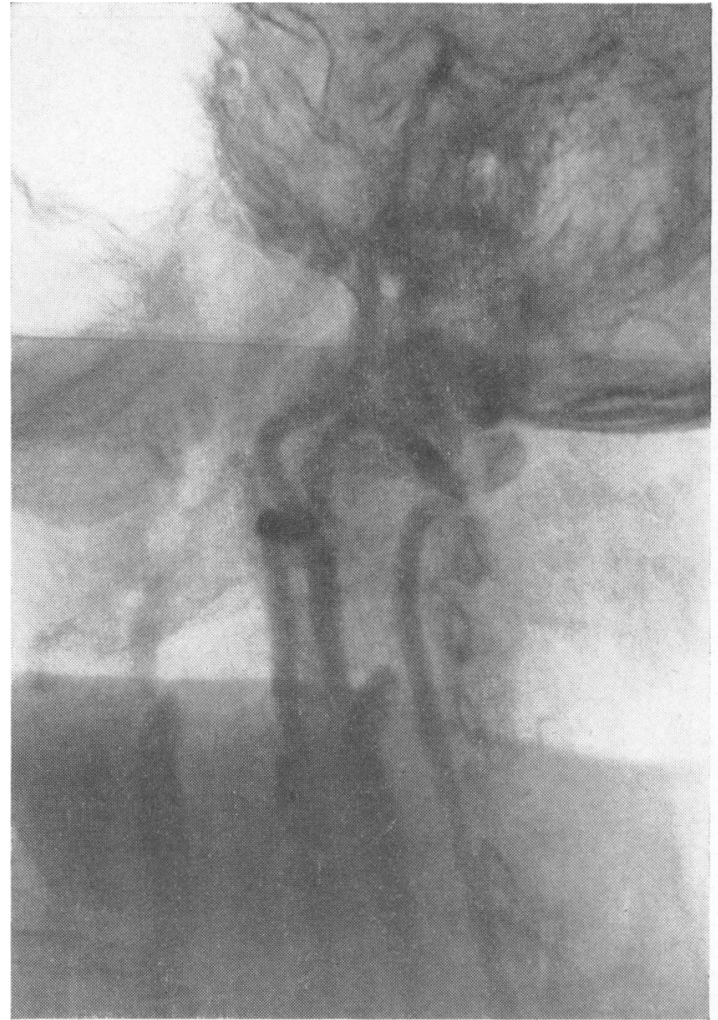

FIG. 2. Four-vessel angiography (subtraction film) showing occlusion of both carotid arteries just distal to their points of origin.

vertebrobasilar transient ischaemic attacks as in those with such attacks in the carotid territory.

TABLE V

INDENTATION OF VERTEBRAL ARTERIES BY OSTEOPHYTES IN 39 PATIENTS SUBJECTED TO FOUR-VESSEL ANGIOGRAPHY

\begin{tabular}{|c|c|c|c|c|}
\hline Transient Ischaemic & Attack & $\begin{array}{l}\text { No. of } \\
\text { Patients }\end{array}$ & $\begin{array}{l}\text { No. with } \\
\text { Indentation }\end{array}$ & Percentage \\
\hline $\begin{array}{l}\text { Carotid } \\
\text { Vertebrobasilar }\end{array}$ & & $\begin{array}{l}15 \\
24\end{array}$ & $\begin{array}{r}3 \\
10\end{array}$ & $\begin{array}{l}20 \\
41\end{array}$ \\
\hline CORRELATION & OF & $\begin{array}{l}\text { ANGIOGR } \\
\text { FINDIN }\end{array}$ & AND & CLINICAL \\
\hline
\end{tabular}

An examination was made of the frequency and duration of the transient ischaemic attacks in relation to the angiographic findings without any correlation being found; patients with more prolonged or more frequent attacks did not have a higher incidence of stenoses. The presence of a bruit, on the other hand, did increase the probability of finding a stenosis at angiography. Thus of 21 patients with a bruit, 12 


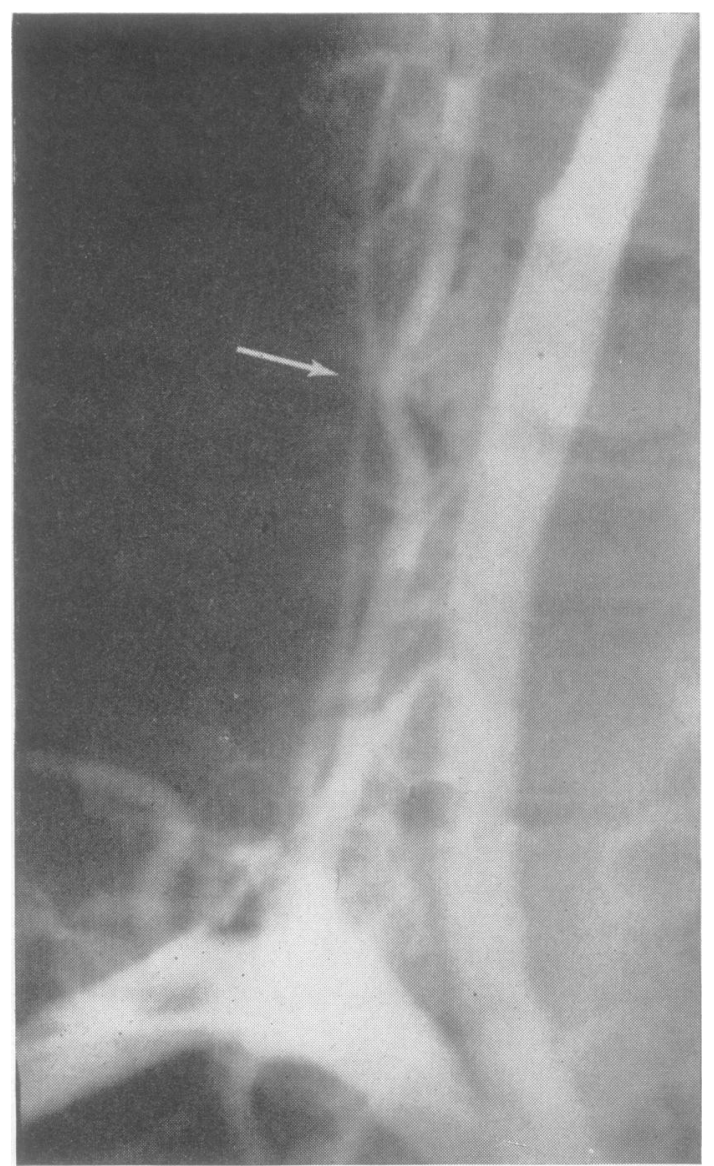

FIG. 3. Angiographic demonstration of indentation of right vertebral artery by osteophytes.

(57\%) had a stenosis, whereas among 38 patients without a bruit only eight ( $21 \%)$ had a stenosis.

Although it was difficult to predict in advance whether or not a stenosis would be found, apart from those cases with a bruit, the angiographic findings often confirmed in a striking fashion the presumed anatomical site of the lesion. A woman of 54 years (C.V. no. 622) had two episodes of severe vertigo accompanied by nausea and vomiting. Angiography revealed a severe stenosis of the basilar artery (Fig. 4); in addition she had a stenosis at the origin of the right internal carotid artery.

One other feature worthy of comment was the time interval that had elapsed between the first transient ischaemic attack and the appearance of the patient in the clinic. Among patients with transient ischaemic attacks in the carotid territory it averaged 2.7 months for those with a stenosis and 4.6 months for those without; among patients

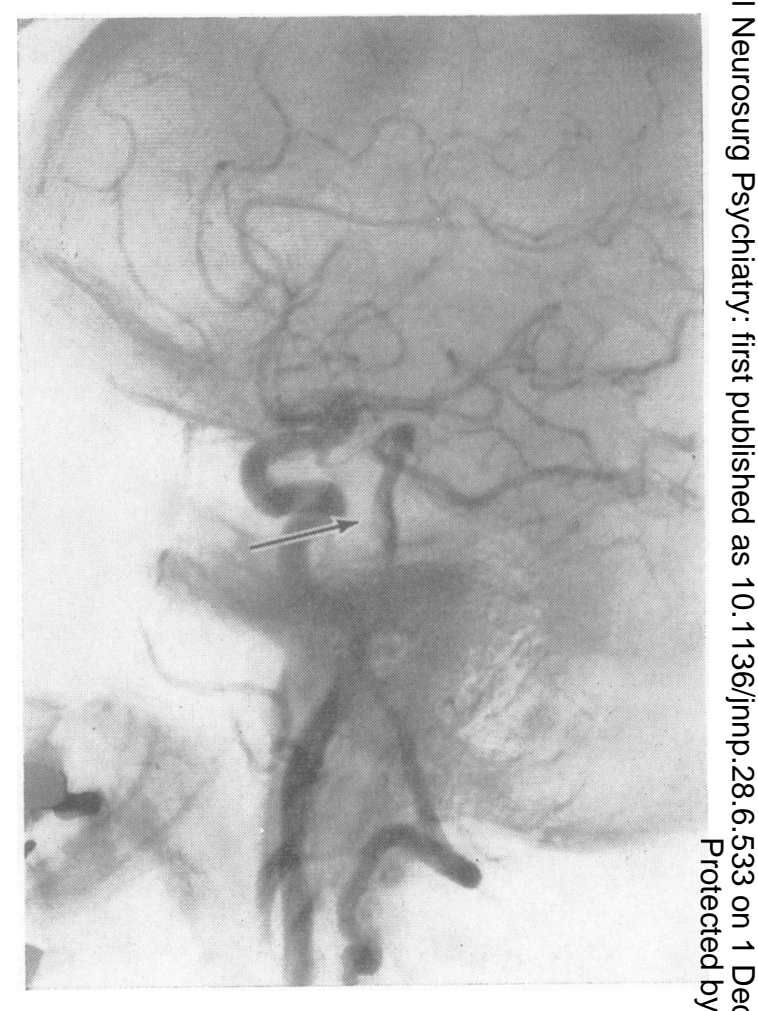

FIG. 4. Subtraction film showing a filling defect on ther anterior wall of the mid-portion of the basilar artery.

with attacks in the vertebrobasilar territory it averaged nine months for those with a stenosis and 11 months for those without.

The difficulty of being certain that the clinical picture is due to the angiographic lesion is well illustrated by the two patients with stenosis of the $\frac{\approx}{\nabla}$ innominate artery. The first was a woman of 55 years $\stackrel{D}{2}$ (C.V. no. 693) who gave a history of episodes of $\overrightarrow{\overrightarrow{0}}$ vertigo, diplopia, and disturbed consciousness of 3 about 20 minutes' duration. Examination during the $\rightleftharpoons$ attacks showed her to have nystagmus and disturbance of eye movements. She had a harsh bruit in the right supraclavicular fossa and angiography revealed a mild degree of stenosis of the innominate artery (Fig. 5a). The suggestion was made that emboli were arising from this site and being carried $\delta$ to the basilar artery. While this suggestion might $₹$ appear highly speculative, its reasonableness was 0 well illustrated by the other case of a man of $46 \overrightarrow{7}$ years (C.V. no. 698). One day he developed an epi-음 sode of blurred vision affecting the entire field of both eyes and persisting for 45 minutes. During the $O$ following night he was awakened by excruciating $N$ 


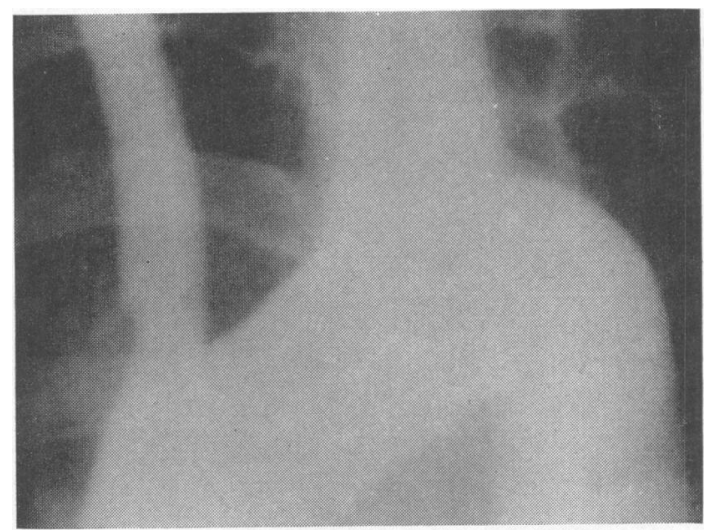

FIG. 5a. Filling defect in the innominate artery just distal to its point of origin.

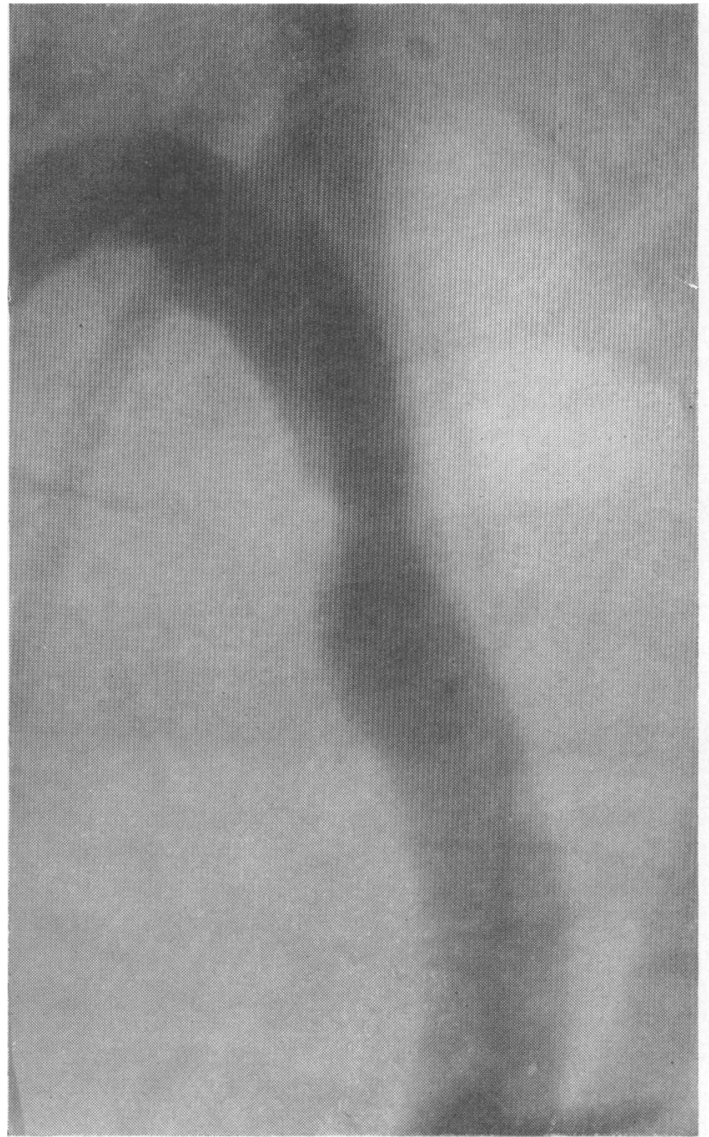

FIG. 5b. Filling defect in the innominate artery just distal to its point of origin (subtraction film). pain in the right forearm; this remained intense for 48 hours and then gradually diminished over the course of a week. The tip of the right index finger was blanched at the onset of the pain and subsequently became blackened. Six weeks later, while lying in bed, he had an episode of loss of consciousness during which he adopted a position which, from his wife's description, is characteristic of decerebrate rigidity. This persisted for about half an hour and then subsided. Next morning he was quite well. On examination he had a harsh bruit in the right supraclavicular fossa and angiography revealed a stenosis of the innominate artery (Fig. 5b). The incident involving the right upper limb was so typical of an embolic episode that it strengthens the presumption that the basilar episodes were of similar aetiology.

\section{TREATMENT}

This report is not primarily concerned with therapy because until more is known about the aetiology and differential diagnosis of the various types of transient ischaemic attack the indications for therapy will remain uncertain. In this series, however, two patients underwent endarterectomy for internal carotid stenosis with benefit. The patient with the subclavian steal syndrome had a successful disobliteration of the subclavian artery. One patient, whose vertebrobasilar transient ischaemic attacks were precipitated by neck movements, had a kink in the first part of the vertebral artery, due to constriction by a fibrous band, relieved. The male patient with the innominate stenosis was advised to have surgery but declined. Sixteen patients were started on anticoagulant therapy, two on hypotensive therapy, and three were fitted with plastic collars. The remaining patients are being kept under observation.

\section{DISCUSSION}

The results of the present study leave no doubt as to the diagnostic value of angiography in patients with transient ischaemic attacks. They confirm the findings of Poser et al. (1962) who found abnormalities in $74 \%$ of 89 patients with intermittent cerebrovascular insufficiency. They also show that visualization of a single vessel is inadequate; the entire course of all four vessels supplying the brain from their origins at the aortic arch must be outlined if a full assessment of the state of the cerebral arterial supply is to be made. This was well illustrated by the patient who was experiencing attacks of loss of vision in both visual fields. Such a symptom would undoubtedly draw attention to the vertebrobasilar tree and could have been due to emboli in this part of the arterial 
system. Four-vessel angiography revealed occlusions of both internal carotid arteries, a finding which lead to the conclusion that falls in blood flow were probably responsible for the attacks.

The finding of lesions in more than one vessel was to be expected from the pathological studies of Hutchinson and Yates (1957) and Schwartz and Mitchell (1961) who demonstrated that stenotic lesions are commonly multiple. The practical implications of this are clear; surgery of one vessel cannot be contemplated without accurate knowledge of the state of the remaining vessels. This knowledge can now be obtained with relative simplicity, little discomfort, and a high degree of safety by means of a catheter passed via the right axillary artery. With this method the origin of the great vessels from the aorta can be visualized, the right side of the circulation almost invariably demonstrated, and the left side seen in about two-thirds of the cases. When further information about the left side of the circulation is required it may be obtained by a catheter passed via the left axillary artery or by direct puncture of the left carotid.

Although the angiographic demonstration of the arterial tree is the first step towards rational treatment, its satisfactory accomplishment does not solve all problems. There remains the difficult task of relating the stenotic lesions demonstrated to the symptoms of the patient. Stenoses may affect the cerebral circulation in two ways; they may be of such degree as to interfere with blood flow, or they may provide a site for the formation of thrombi from which emboli may be carried to the cerebral vessels.

It is unwise to postulate too readily that a stenosis may be causing a reduction in cerebral blood flow, for Brice, Dowsett, and Lowe (1964) have demonstrated that the lumen of the internal carotid artery must be reduced to 2 square $\mathrm{mm}$. before there is a significant reduction of blood flow through the vessel. It must also be remembered that any reduction of flow through a single vessel may well be completely compensated by increased flow through anastomotic channels (Stern, 1962), though in this regard the observations of Alpers, Berry, and Paddison (1959) that in about $27 \%$ of cases there are variations in the circle of Willis which will interfere with its efficiency as an anastomotic channel, must be borne in mind. There can be no doubt, however, that stenoses may be so severe that they interfere with cerebral flow in man. This was shown by Adams, Smith, and Wylie (1963), who found a significant reduction in total cerebral blood flow, as measured by the KetySchmidt nitrous oxide technique, in patients with stenotic lesions at the origins of the great vessels from the aorta and in those with bilateral stenotic lesions of the common or internal carotid arteries associated with similar lesions in the vertebrobasilar systems. $\bar{z}$ The cerebral blood flow was restored to normal by endarterectomy. They did not find any reduction in total cerebral blood flow in patients with single stenotic or occlusive lesions; the method used did not $\stackrel{\theta}{0}$ enable them to measure regional flow.

The alternative method by which stenoses may influence the cerebral circulation is by providing a source of emboli. Evidence of this has been produced $\vec{z}$ by Gunning, Pickering, Robb-Smith, and Ross Russell (1964). They observed patients with transient $\stackrel{\vec{\rho}}{9}$ attacks of blindness in whom angiography demon- $\overline{0}$ strated a stenosis of the ipsilateral internal carotid $\underline{\underline{0}}$ artery which, at operation, was found to be the site $\frac{\bar{\rho}}{\bar{\sigma}}$ of fresh, friable platelet-fibrin thrombus.

The distinction between these two possibilities can in part be made upon the basis of the angio- $s$ graphic findings. A mild degree of stenosis, as $\vec{\circ}$ illustrated in Fig. 5, is clearly not causing any $\overrightarrow{\vec{\omega}}$ reduction in flow but may well be a source of emboli. $\stackrel{\sigma}{\sigma}$ On the other hand, multiple occlusions and stenoses as illustrated in Fig. 2 are very likely to be associated with a reduction in cerebral blood flow. The patho- i physiology of these two situations is clearly distinct, 0 and the treatment required obviously differento of Unless they have been distinguished by angiograph therapy cannot proceed on a rational basis.

A final point which deserves mention is th $\vec{B}$ frequency with which one or both vertebral arteries were grossly indented by osteophytes in patients $\Phi$ experiencing transient ischaemic attacks in the $\bar{g}$ vertebrobasilar territory. The higher incidence of thr. 므. phenomenon as compared with patients experiencin $\overrightarrow{8}$ carotid transient ischaemic attacks and the demon- 8 stration by Sheehan, Bauer, and Meyer (1960) of increased indentation of these vessels during movement of the neck, indicate that this mechanism may be responsible for a higher proportion of transient ischaemic attacks than was hitherto suspected. This possibility should be entertained in all patients who $\stackrel{\square}{\unrhd}$ relate episodes of vertebrobasilar ischaemia to neck $\overrightarrow{\overrightarrow{0}}$ movements, or in whom their 'spontaneous' attacks 3 can be reproduced by rotation of the neck. Relief of this condition can be achieved by immobilization of the neck with a collar or, in cases in which there is a single rather than multiple indentations, by surgery (Hardin, Williamson, and Steegmann, 1960; Gortvai, 1964).

\section{SUMMARY}

In a consecutive series of 66 patients who presented with transient ischaemic attacks 59 were studied by $\frac{D}{0}$ angiography. The percentage of patients with arteriographic abnormalities rose from $14 \%$ when $N$ one vessel was examined, to $66 \%$ when four vessels $N$ 
were examined. There was a higher incidence of abnormalities in patients with bruits than in those without. Four-vessel angiography via the axillary artery is a safe procedure in patients with transient ischaemic attacks and provides valuable information without which rational therapy is not possible.

The surgery on these patients was carried out by Mr. B. N. Catchpole, Mr. H. H. G. Eastcott, Mr. Valentine Logue, and Professor G. W. Taylor.

The work was supported by a grant from the British Heart Foundation to one of us.

\section{REFERENCES}

Adams, J. E., Smith, M. C., and Wylie, E. J. (1963). Cerebral blood flow and haemodynamics in extracranial vascular disease: Effect of endarterectomy. Surgery, 53, 449-455.

Alpers, B. J., Berry, R. G., and Paddison, R. M. (1959). Anatomical studies of the circle of Willis in normal brain. A.M.A. Arch. Neurol. Psychiat., 81, 409-418.

Bauer, R., Sheehan, S., and Meyer, J. S. (1961). Arteriographic study of cerebrovascular disease. II. Cerebral symptoms due to kinking, tortuosity, and compression of carotid and vertebral arteries in the neck. Arch. Neurol. (Chic.), 4, 119-131.

Brice, J. G., Dowsett, D. J., and Lowe, R. D. (1964). Haemodynamic effects of carotid artery stenosis. Brit. med. J., 2, 1363-1366.

Crawford, T. (1956). The pathological effects of cerebral arteriography. J. Neurol. Neurosurg. Psychiat., 19, 217-221.

Denny-Brown, D., and Meyer, J. S. (1957). The cerebral collateral circulation. 2. Production of cerebral infarction by ischaemic anoxia and its reversibility in early stages. Neurology (Minneap.), 7, 567-579.

Gunning, A. J., Pickering, G. W., Robb-Smith, A. H. T., and Ross Russell, R. (1964). Mural thrombosis of the internal carotid artery and subsequent embolism Quart.J. Med., 33, 155-195.

Gortvai, P. (1964). Insufficiency of vertebral artery treated by decompression of its cervical part. Brit. med. J., 2, 233-234.
Gurdjian, E. S., Lindner, D. W., Hardy, W. G., and Webster, J. E (1960). Cerebrovascular disease: an analysis of 600 cases Neurology (Minneap.), 10, 372-380.

Hardin, C. A., Williamson, W. P., and Steegmann, A. T. (1960). Vertebral artery insufficiency produced by cervical ostecarthritic spurs. Ibid., 10, 855-858.

Hutchinson, E. C., and Stock, J. P. P. (1963). Paroxysmal cerebral ischaemia in rheumatic heart-disease. Lancet, 2, 653-656.

- , and Yates, P. O. (1957). Carotico-vertebral stenosis. Ibid., 1, 2-8.

Kendell, R. E., and Marshall, J. (1963). Role of hypotension in the genesis of transient focal cerebral ischaemic attacks. Brit. med. J., 2, 344-348.

Marshall, John (1964). The natural history of transient ischaemic cerebro-vascular attacks. Quart. J. Med., 33, 309-324.

Meyer, J. S., Sheehan, S., and Bauer, R. B. (1960.) An arteriographic study of cerebrovascular disease in man. I. Stenosis and occlusion of the vertebral-basilar arterial system. Arch. Neurol. (Chic.), 2, 27-45.

Millikan, C. H., Siekert, R. G., and Whisnant, J. P. (1960). Intermittent carotid and vertebral-basilar insufficiency associated with polycythen ia. Neurology (Minneap.), 10, 188-196.

Müller, R., Greitz, T., Liliequist, B., and Hellstrom, L. (1964). Aortocervical angiography in occlusive cerebrovascular disease. Ibid., 14, 136-146.

Newton, T. H. (1963). The axillary artery approach to arteriography of the aorta and its branches. Amer. J. Roentgenol., 89, 275-283.

Poser, C. M., Snodgrass, R. G., and Faris, A. A. (1962). Radiologic visualization of neck vessels in cerebrovascular insufficiency. J. Amer. med. Ass., 182, 126-131.

Schwartz, C. J., and Mitchell, J. R. A. (1961). Atheroma of the carotid and vertebral arterial systems. Brit. med. J., 2, 1057-1063.

Sheehan, S., Bauer, R B., and Meyer, J. S. (1960). Vertebral artery compression in cervical spondylosis. Arteriographic demonstration during life of vertebral artery insufficiency due to rotation and extension of the neck. Neurology (Minneap.), 10, 968-986.

Siekert, R. G., Whisnant, J. P., and Millikan, C H. (1960). Anemia and intermittent focal cerebral arterial insufficiency. A.M.A. Arch. Neurol., 3, 386-390.

Stern, W. E. (1962). A preliminary report of experimental and clinical observations upon cervical carotid artery blood flow. J. Neurol. Neurosurg. Psychiat., 25, 303-314. 